\title{
The fuzzy-controller for WiMAX networks
}

\author{
Olena Semenova, Andriy Semenov \\ Faculty of Radio Engineering, Telecommunication and \\ Instrument Engineering \\ Vinnytsia National Technical University \\ Vinnytsia, Ukraine \\ Helene_S@ukr.net
}

\author{
Oleksandr Voznyak, Dmytro Mostoviy, Igor Dudatyev \\ Faculty of Automatics, Electronics and Computer Control \\ Systems \\ Vinnytsia National Technical University \\ Vinnytsia, Ukraine \\ voznyakaleksandr@mail.ru
}

\begin{abstract}
WiMAX is a broadband wireless last mile technology providing high speeds for long distances and offering great flexibility. Scheduling in WiMAX became one of the most important tasks, because it is responsible for distributing available resources among users. A high level of quality of service and scheduling support is one of the most interesting features of the WiMAX standard. In modern telecommunication networks the access control techniques are widely used. That is because using such devices instead of traditional ones permits to increase accuracy and reliability of control. Fuzzy systems have replaced conventional techniques in many engineering applications, especially in control systems. In the article it is suggested to use a fuzzy controller for access control in WiMAX networks that allows avoiding congestion in networks. The main objective of this work is providing an implementation of the WiMAX standard using the dynamic fuzzy logic based priority scheduler. We propose to use a fuzzy controller having three input and one output linguistic variables. Input linguistic variables of the controller are waiting time, queue length and packet size, its output variable is priority. A block diagram of the fuzzy controller was developed. Linguistic variables, terms and membership functions for input and output values have been defined. The Waiting time linguistic variable has three terms: low, medium, high. The Queue length linguistic variable has three terms: short, medium, long. The Packet size linguistic variable has three terms: small, medium, large. The rules base consisting of twenty-seven rules has been developed. The fuzzy controller has been simulated using Matlab 6.5. Results of the simulation prove the accuracy and reliability of the fuzzycontroller's model.
\end{abstract}

\section{Keywords-WiMAX; fuzzy-controller; simulation}

\section{INTRODUCTION}

Nowadays there are many kinds of wireless access technologies available to satisfy different needs and requirements of users in the heterogeneous wireless environment, such as WiFi, WiMAX and UTRAN [1]. The main feature of the heterogeneous wireless environment is that all the users can switch different access technologies according to their needs. For supporting multiple applications with different QoS requirements, efficient resource management and call admission control strategies are required.
The network state changes consistently. Therefore, static resource reservation mechanism can not adjust properly. Thus, a fuzzy controller used in the resource reservation mechanism changes parameters dynamically and adaptively.

Fuzzy logic refers to a logical system that generalizes classical logic for reasoning under uncertainty [2]. In general sense, fuzzy logic refers to all the theories and techniques employing fuzzy sets, i.e. classes with rough confines. Fuzzy logic implements human experiences by means of membership functions and fuzzy rules. Fuzzy logic can be used when dealing with uncertain information while a network shows dynamic nature.

Generally a fuzzy controller consists of four main blocks: a fuzzifier, defuzzifier, inference engine, and fuzzy rule base.

The purpose of the fuzzy controller used in telecommunication networks is to adjust dynamically the realtime service bandwidth and to enhance the resource reservation mechanism. Inefficient resource allocation may cause misutilization of network resources or an excessive traffic delay. Also the fuzzy controller can be implemented for adjusting adaptively the amount of the allocated bandwidth for new calls according to new network conditions.

One of the most interesting features of the WiMAX standard technology is a high level of QoS and scheduling support.

Scheduling algorithms determine which packet is to be served next amongst all the packets in the queue. A scheduler works as a resource allocator to share limited resources served by a base station. The fuzzy logic based scheduler fulfils the task of scheduling the data packets.

Thus, we examine the possibility to implement a dynamic scheduling block, where the scheduler depends on the incoming traffic. We propose a new fuzzy logic based scheduler to improve the operability of the WiMAX network.

\section{ARCHITECTURE OF THE FUZZY CONTROLLER}

We propose to use in the WiMAX networks a fuzzy controller having three input and one output linguistic variables (fig.1). Input linguistic variables of the fuzzy- 
controller are the waiting time WT, the queue length QL, and the packet size PS, its output variable is the priority $\mathrm{P}$.

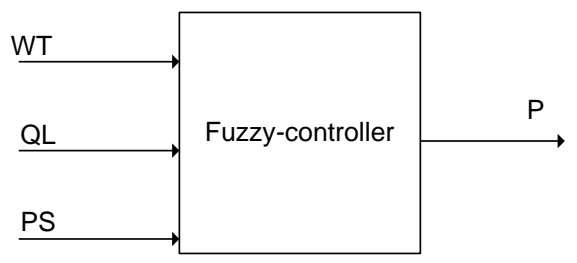

Fig. 1. The architecture of the fuzzy-controller

\section{MEMBERSIP FUNCTIONS}

For defining the waiting time WT terms "low", "medium", and "high" are used. Thus, the term set of the number of the waiting time WT is

$$
\mathrm{T}(\mathrm{WT})=\{\text { Low }(\mathrm{Lw}), \operatorname{Medium}(\mathrm{M}), \operatorname{High}(\mathrm{H})\}
$$

Membership functions for T(WT) are presented on fig. 2.

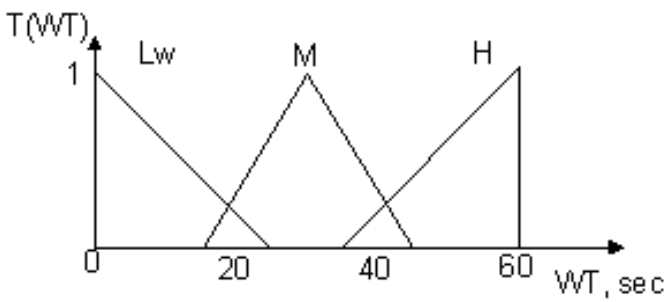

Fig. 2. Membership functions for the WT linguistic variable

For defining the queue length QL terms "short", "medium", and "long" are used. Thus, the term set of the number of the queue length QL is

$$
\mathrm{T}(\mathrm{QL})=\{\text { Short (Sh), Medium (M), Long (Ln) }\}
$$

Membership functions for $\mathrm{T}(\mathrm{QL})$ are presented on fig. 3.

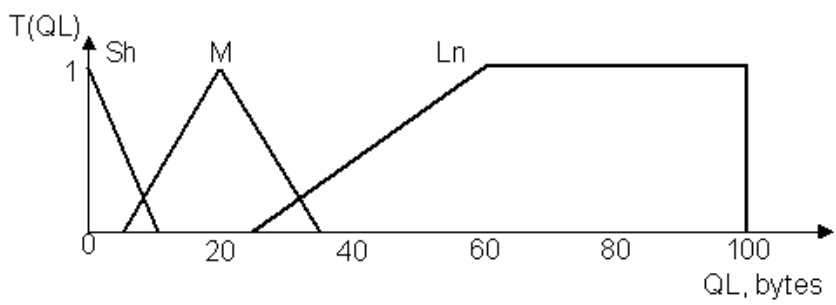

Fig. 3. Membership functions for the QL linguistic variable

For defining the packet size PS terms "small", "medium", and "large" are used. Thus, the term set of the number of the packet size PS is

$$
\mathrm{T}(\mathrm{QL})=\{\text { Small }(\mathrm{Sm}), \text { Medium }(\mathrm{M}), \text { Large }(\mathrm{Lg})\}
$$

Membership functions for T(PS) are presented on fig. 4.

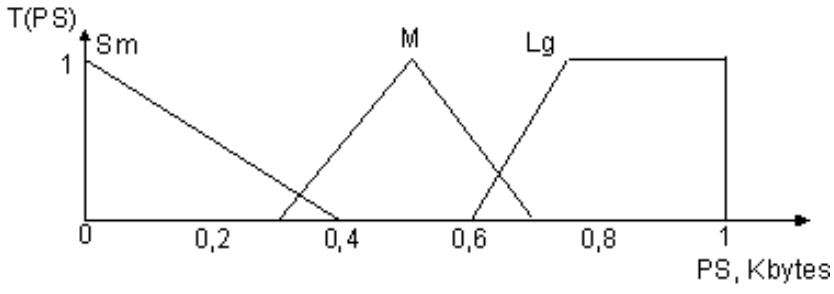

Fig. 4. Membership functions for the PS linguistic variable

For defining the priority P the terms "very low", "low", "medium", "high", "very high" are used. Thus, the term set for the subscriber's priority $\mathrm{P}$ is

$\mathrm{T}(\mathrm{WT})=\{$ Very low $(\mathrm{VL})$, Low $(\mathrm{Lw}), \operatorname{Medium}(\mathrm{M}), \operatorname{High}(\mathrm{H})$, Very high (VH)\}

Membership functions for $\mathrm{T}(\mathrm{P})$ are presented on fig. 5 .

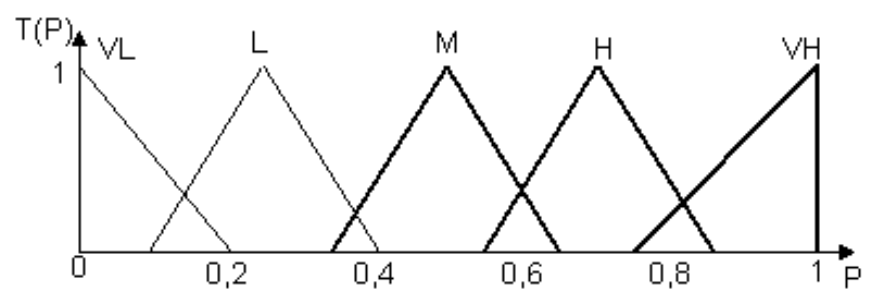

Fig. 5. Membership functions for the $\mathrm{P}$ linguistic variable

The proposed fuzzy controller works according to a rules base consisting of twenty-seven rules:

1. If $\mathrm{WT}=\mathrm{LW}$ and $\mathrm{QL}=\mathrm{Sh}$ and $\mathrm{PS}=\mathrm{Sm}$ than $\mathrm{P}=\mathrm{VL}$;

2. If $\mathrm{WT}=\mathrm{Lw}$ and $\mathrm{QL}=\mathrm{Sh}$ and $\mathrm{PS}=\mathrm{M}$ than $\mathrm{P}=\mathrm{VL}$;

3. If $\mathrm{WT}=\mathrm{Lw}$ and $\mathrm{QL}=\mathrm{Sh}$ and $\mathrm{PS}=\mathrm{Lg}$ than $\mathrm{P}=\mathrm{L}$;

4. If $\mathrm{WT}=\mathrm{Lw}$ and $\mathrm{QL}=\mathrm{M}$ and $\mathrm{PS}=\mathrm{Sm}$ than $\mathrm{P}=\mathrm{VL}$;

5. If $\mathrm{WT}=\mathrm{Lw}$ and $\mathrm{QL}=\mathrm{M}$ and $\mathrm{PS}=\mathrm{M}$ than $\mathrm{P}=\mathrm{L}$;

6. If $\mathrm{WT}=\mathrm{LW}$ and $\mathrm{QL}=\mathrm{M}$ and $\mathrm{PS}=\mathrm{Lg}$ than $\mathrm{P}=\mathrm{M}$;

7. If $\mathrm{WT}=\mathrm{Lw}$ and $\mathrm{QL}=\mathrm{Ln}$ and $\mathrm{PS}=\mathrm{Sm}$ than $\mathrm{P}=\mathrm{VL}$;

8. If $\mathrm{WT}=\mathrm{Lw}$ and $\mathrm{QL}=\mathrm{Ln}$ and $\mathrm{PS}=\mathrm{M}$ than $\mathrm{P}=\mathrm{VL}$; 
9. If $\mathrm{WT}=\mathrm{LW}$ and $\mathrm{QL}=\mathrm{Ln}$ and $\mathrm{PS}=\mathrm{Lg}$ than $\mathrm{P}=\mathrm{L}$;

10. If $\mathrm{WT}=\mathrm{M}$ and $\mathrm{QL}=\mathrm{Sh}$ and $\mathrm{PS}=\mathrm{Sm}$ than $\mathrm{P}=\mathrm{L}$;

11. If $\mathrm{WT}=\mathrm{M}$ and $\mathrm{QL}=\mathrm{Sh}$ and $\mathrm{PS}=\mathrm{M}$ than $\mathrm{P}=\mathrm{L}$;

12. If $\mathrm{WT}=\mathrm{M}$ and $\mathrm{QL}=\mathrm{Sh}$ and $\mathrm{PS}=\mathrm{Lg}$ than $\mathrm{P}=\mathrm{L}$;

13. If $\mathrm{WT}=\mathrm{M}$ and $\mathrm{QL}=\mathrm{M}$ and $\mathrm{PS}=\mathrm{Sm}$ than $\mathrm{P}=\mathrm{L}$;

14. If $\mathrm{WT}=\mathrm{M}$ and $\mathrm{QL}=\mathrm{M}$ and $\mathrm{PS}=\mathrm{M}$ than $\mathrm{P}=\mathrm{M}$;

15. If $\mathrm{WT}=\mathrm{M}$ and $\mathrm{QL}=\mathrm{M}$ and $\mathrm{PS}=\mathrm{Lg}$ than $\mathrm{P}=\mathrm{H}$;

16. If $\mathrm{WT}=\mathrm{M}$ and $\mathrm{QL}=\mathrm{Ln}$ and $\mathrm{PS}=\mathrm{Sm}$ than $\mathrm{P}=\mathrm{L}$;

17. If $\mathrm{WT}=\mathrm{M}$ and $\mathrm{QL}=\mathrm{Ln}$ and $\mathrm{PS}=\mathrm{M}$ than $\mathrm{P}=\mathrm{L}$;

18. If $\mathrm{WT}=\mathrm{M}$ and $\mathrm{QL}=\mathrm{Ln}$ and $\mathrm{PS}=\mathrm{Lg}$ than $\mathrm{P}=\mathrm{M}$;

19. If $\mathrm{WT}=\mathrm{H}$ and $\mathrm{QL}=\mathrm{Sh}$ and $\mathrm{PS}=\mathrm{Sm}$ than $\mathrm{P}=\mathrm{M}$;

20. If $\mathrm{WT}=\mathrm{H}$ and $\mathrm{QL}=\mathrm{Sh}$ and $\mathrm{PS}=\mathrm{M}$ than $\mathrm{P}=\mathrm{M}$;

21. If $\mathrm{WT}=\mathrm{H}$ and $\mathrm{QL}=\mathrm{Sh}$ and $\mathrm{PS}=\mathrm{Lg}$ than $\mathrm{P}=\mathrm{H}$;

22. If $\mathrm{WT}=\mathrm{H}$ and $\mathrm{QL}=\mathrm{M}$ and $\mathrm{PS}=\mathrm{Sm}$ than $\mathrm{P}=\mathrm{M}$;

23. If $\mathrm{WT}=\mathrm{H}$ and $\mathrm{QL}=\mathrm{M}$ and $\mathrm{PS}=\mathrm{M}$ than $\mathrm{P}=\mathrm{H}$;

24. If $\mathrm{WT}=\mathrm{H}$ and $\mathrm{QL}=\mathrm{M}$ and $\mathrm{PS}=\mathrm{Lg}$ than $\mathrm{P}=\mathrm{VH}$;

25. If $\mathrm{WT}=\mathrm{H}$ and $\mathrm{QL}=\mathrm{Ln}$ and $\mathrm{PS}=\mathrm{Sm}$ than $\mathrm{P}=\mathrm{M}$;

26. If $\mathrm{WT}=\mathrm{H}$ and $\mathrm{QL}=\mathrm{Ln}$ and $\mathrm{PS}=\mathrm{M}$ than $\mathrm{P}=\mathrm{M}$;

27. If $\mathrm{WT}=\mathrm{H}$ and $\mathrm{QL}=\mathrm{Ln}$ and $\mathrm{PS}=\mathrm{Lg}$ than $\mathrm{P}=\mathrm{H}$.

\section{SimULATION}

In order to confirm the operability of the fuzzy-controller we can use the Matlab 6.5 program [3]. It is a multi-paradigm numerical computing environment and fourth-generation programming language. The simulated fuzzy-controlles is shown on fig. 6 .

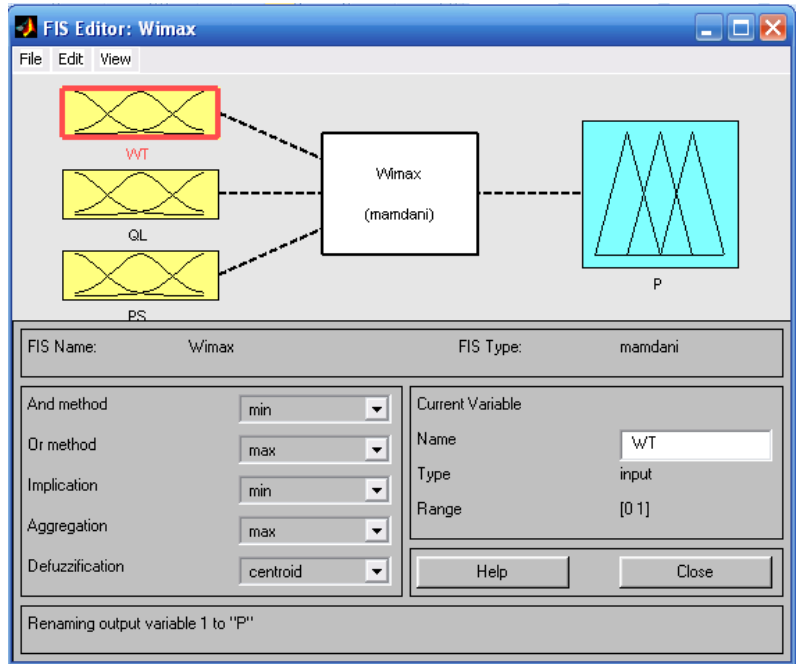

Fig. 6. The fuzzy-controller in Matlab 6.5

Specifying of the waiting time input linguistic variable is shown on fig.7.

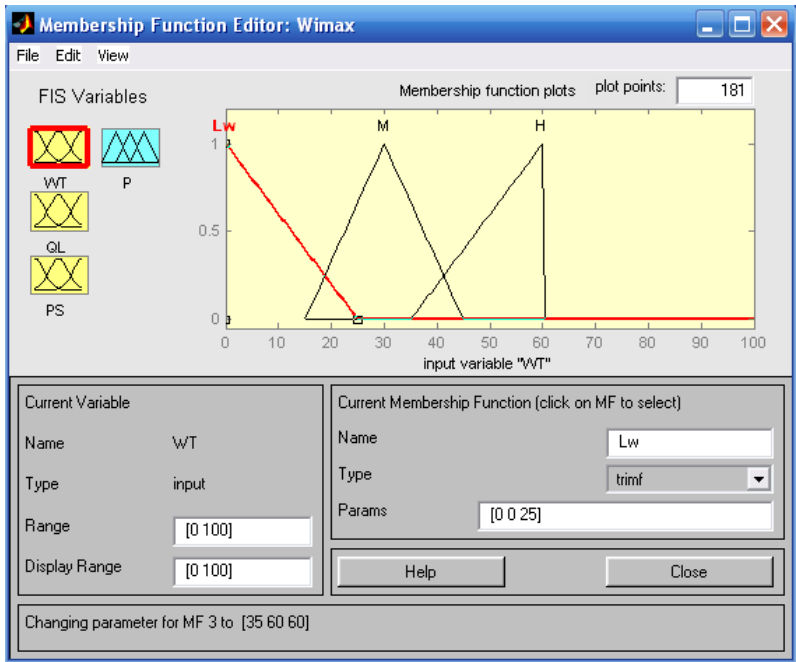

Fig. 7. Specifying of the WT input variable

Specifying of the queue length input linguistic variable is shown on fig.8. Specifying of the packet size input linguistic variable is shown on fig.9. Specifying of the priority output linguistic variable is shown on fig.10. Specifying of the rule base is shown on fig. 11 .

Let the waiting time $\mathrm{WT}=55$, the queue length $\mathrm{QL}=70$, and the packet size $\mathrm{PS}=0.9$. According to fig. 12 we get the priority value $\mathrm{P}=0.7$ 


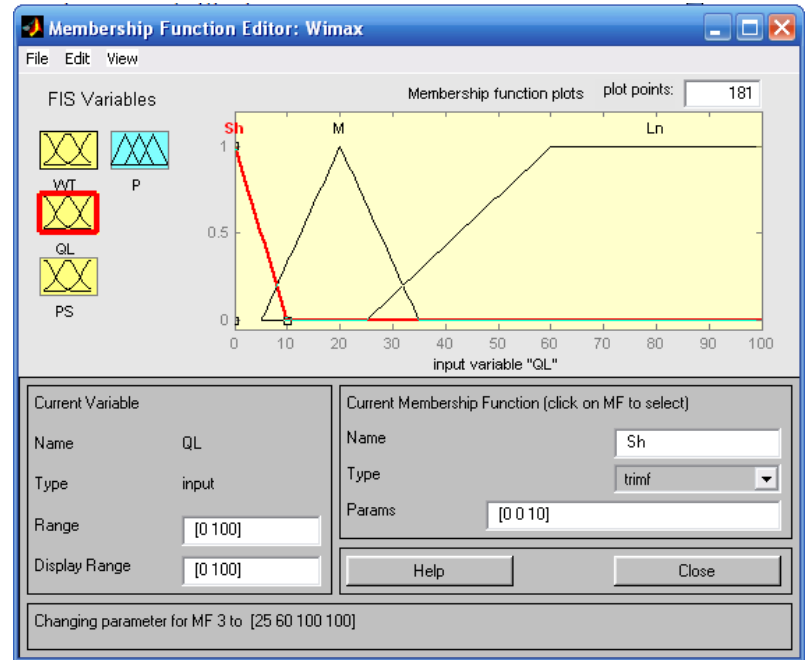

Fig. 8. Specifying of the QL input variable

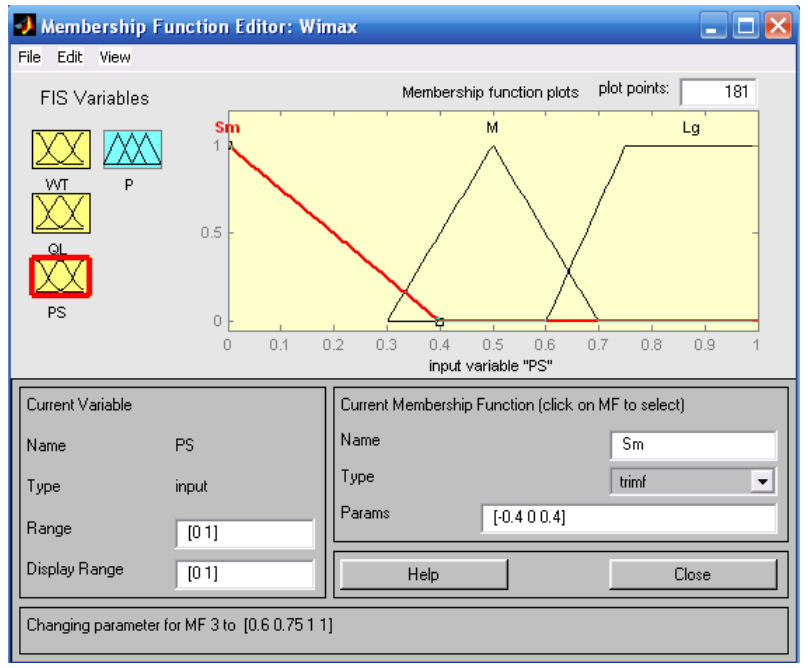

Fig. 9. Specifying of the PS input variable

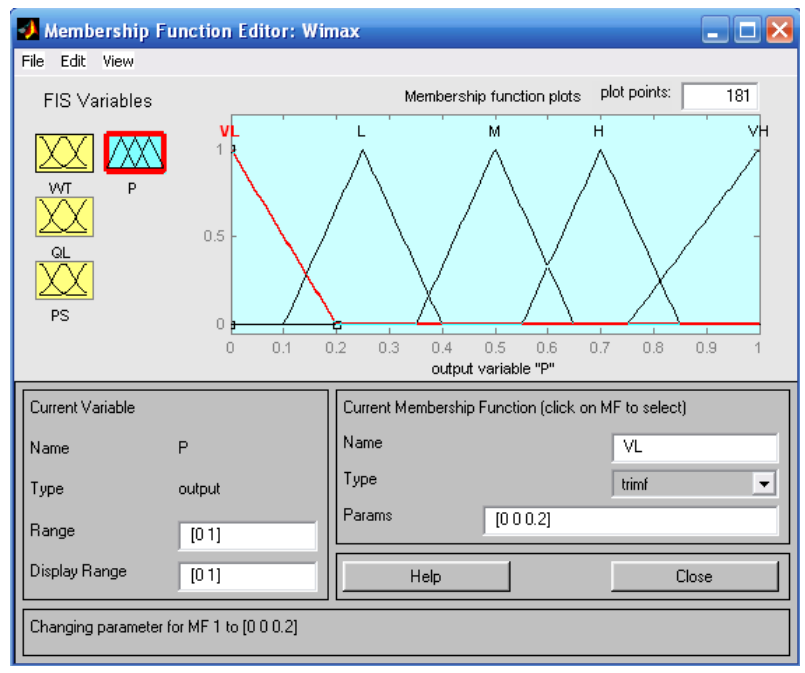

Fig. 10. Specifying of the P output variable

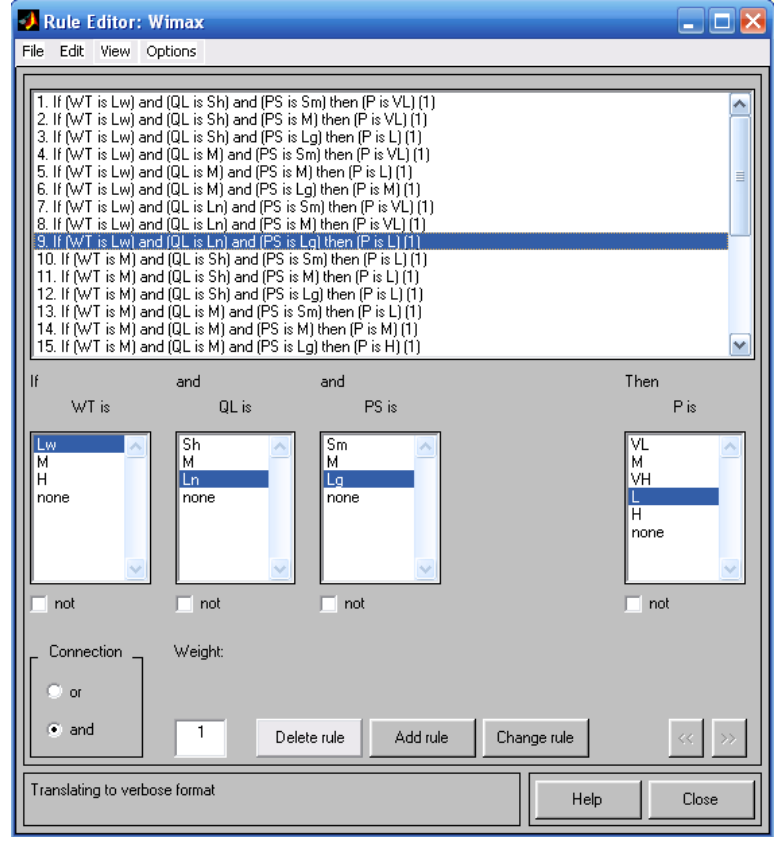

Fig. 11. The rule base

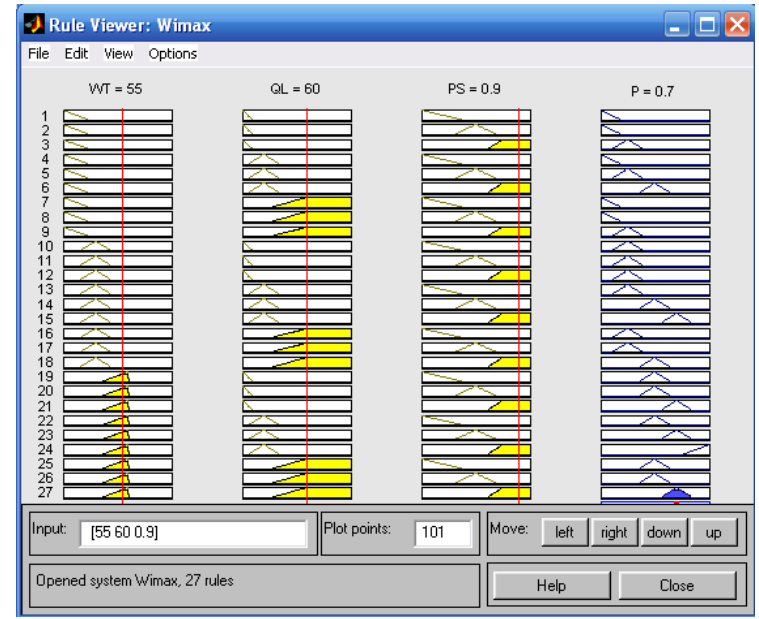

Fig. 12. The simulation result

\section{References}

[1] I-Shyan Hwang, Bor-Jiunn Hwang, K. Robert Lai, Ling-Feng Ku, Chien-Chieh Hwang. Adaptive QoS-aware Resource Management in Heterogeneous Wireless Networks // Proc of the 22nd International Conference on Advanced Information Networking and Applications. 2008. - P. 880-805

[2] . Kumar D. Performance analysis of AI based QoS scheduler for mobile WiMAX / D. David Neels Pon Kumar, K. Murugesan // ICTACT Journal on Communication Technology. - 2012. - Vol. 3, №.3. - P. 572-579.

[3] Manoj Sharma1, Dr. R.K.Khola. Fuzzy logic based handoverdecision system // International Journal of Ad hoc, Sensor \& Ubiquitous Computing. - 2012. - Vol. 3, №.4. - P. 21-29. 